\title{
DENTAL WEAR CAUSED BY ASSOCIATION BETWEEN BRUXISM AND GASTROESOPHAGEAL REFLUX DISEASE: A REHABILITATION REPORT
}

Naila Aparecida de Godoi MACHADO ${ }^{1}$, Rodrigo Borges FONSECA ${ }^{2}$, Carolina Assaf BRANCO ${ }^{3}$, Gustavo Augusto Seabra BARBOSA ${ }^{4}$, Alfredo Júlio FERNANDES NETO ${ }^{5}$, Carlos José SOARES ${ }^{5}$

\author{
1- Undergraduate student, Dental School, Federal University of Uberlândia, Uberlândia, MG, Brazil. \\ 2- PhD Student, Dental School of Piracicaba, State University of Campinas, Piracicaba, SP, Brazil; Professor, Dental School, Federal University \\ of Uberlândia, Uberlândia, MG, Brazil. \\ 3- MS Graduate student, Dental School, Federal University of Uberlândia, Uberlândia, MG, Brazil. \\ 4- PhD, Professor, Dental School, Federal University of Rio Grande do Norte, Natal, RN, Brazil. \\ 5- PhD, Professor, Dental School, Federal University of Uberlândia, Uberlândia, MG, Brazil.
}

Corresponding address: Dr. Carlos José Soares - Departamento de Dentística Restauradora - Faculdade de Odontologia - Universidade Federal de Uberlândia - Av. Pará, no 1720, Campus Umuarama, 38400-902 - Uberlândia - MG - Brazil - Phone: 5534 32182255; Fax: 553432182279. e-mail: carlosjsoares@umuarama.ufu.br

Received: June 25, 2007 - Accepted: August 02, 2007

\begin{abstract}
$B$ ruxism is a pathological activity of the stomatognathic system that involves tooth grinding and clenching during parafunctional jaw movements. Clinical signs of bruxism are mostly related to dental wear and muscular and joint discomforts, but a large number of etiological factors can be listed, as local, systemic, psychological and hereditary factors. The association between bruxism, feeding and smoking habits and digestive disorders may lead to serious consequences to dental and related structures, involving dental alterations (wear, fractures and cracks), periodontal signs (gingival recession and tooth mobility) and muscle-joint sensivity, demanding a multidisciplinary treatment plan. This paper presents a case report in which bruxism associated with acid feeding, smoking habit and episodes of gastric reflow caused severe tooth wear and great muscular discomfort with daily headache episodes. From the diagnosis, a multidisciplinary treatment plan was established. The initial treatment approach consisted of medical follow up with counseling on diet and smoking habits and management of the gastric disorders. This was followed by the installation of an interocclusal acrylic device in centric relation of occlusion (CRO) for reestablishment of the occlusal stability, vertical dimension of occlusion, anterior guides and return to normal muscle activity (90-day use approximately). After remission of initial symptoms, oral rehabilitation was implemented in CRO by means of full resin composite restorations and new interocclusal device for protection of restorations. Satisfactory esthetics, improved function and occlusal stability were obtained after oral rehabilitation. The patient has attended annual follow-ups for the past 2 years. The multidisciplinary treatment seems to be the key for a successful rehabilitation of severe cases of dental wear involving the association of different health disorders.
\end{abstract}

Uniterms: Bruxism; Gastroesophageal reflux; Dental restoration; Dental occlusion.

\section{INTRODUCTION}

Tooth wear can be defined as a non-carious gradual loss of tooth structure caused by many factors, such as toothto-tooth friction; foreign abrasive substances (i.e., toothbrushing and dentifrice); endogenous chemical factors, like the acid gastric juice present in patients suffering from bulimia or gastroesophageal reflux disease; and exogenous chemical factors from low $\mathrm{pH}$ substances, like citrus fruits 9 . Dentists are often the first health professionals to diagnose dental wear. However, the treatment involves a multidisciplinary approach among family physician, general dentists, prosthodontist, orthodontist and gastroenterologist ${ }^{3}$.

Tooth-to-tooth friction causes the form of wear called attrition. Occlusal and incisal attrition can occur during deglutition and clenching. However, wear becomes more severe during bruxism, as evidenced by the advanced and often rapid wear of the teeth seen in this condition ${ }^{9}$. Clinical signs are matching wear on occluding surfaces, shiny facets on amalgam contacts, enamel and dentin wear and possible fracture of cusps or restorations ${ }^{7}$. Bruxism causes attrition and can be understood as a common parafunctional activity that includes tooth grinding or clenching. It can occur 
without any signs and symptoms, but may become problematic when contributing to increased tooth wear and pain $^{19}$. In accordance to Madrid, et al. ${ }^{15}$ (1998) smokers have a major possibility to develop bruxism symptoms.

Tooth surface loss caused by chemical or electrochemical action is termed corrosion. There are both endogenous and exogenous sources of corrosion. Endogenous sources of corrosion are generally related to systemic diseases, namely bulimia, anorexia ${ }^{14}$ and gastroesophageal reflux disease (GERD) ${ }^{1}$. Corrosion caused by perimolysis (endogenous corrosion) is most marked at palatal surfaces of maxillary anterior teeth and, in severe cases, at the buccal surfaces of posterior teeth. This pattern is consistent with the head's position while vomiting ${ }^{9,11}$. The exogenous sources of corrosion have been related to any food substance with a critical $\mathrm{pH}$ value of less than 5.5, which is known to become a corroding agent and demineralize teeth ${ }^{9}$. This may occur as a result of consuming and/or mulling highly acidic foods and beverages, such as mangoes, lemons and other citrus fruits, drinking carbonated soft drinks and sucking sour candies ${ }^{9}$. Clinical signs are broad concavities within smooth surface enamel, cupping of occlusal surfaces, incisal grooving with dentin exposure, increased incisal translucency, wear on non-occluding surfaces and "raised" amalgam restorations?.

Although some of the individual mechanisms of dental wear may act independently, combined mechanisms occur frequently during the dynamics of interocclusal activity. Attrition-corrosion is the loss of tooth substance due to the action of a corroding agent in areas in which tooth-totooth wear occurs ${ }^{9}$. This process may lead to a loss of vertical dimension, especially in patients with GERD or gastric regurgitation. Irrespective of the causes, the effects of tooth wear are multiple and include altering the vertical dimension of occlusion, muscle pain and spasm and temporomandibular joint (TMJ) pain and dysfunction ${ }^{6}$. Depending on the degree of tooth wear, restorative treatment can range from placement of bonded composites in a few isolated areas of corrosion, to full mouth reconstruction in case of a devastated dentition ${ }^{7}$.

The aim of this study is to report a case describing and discussing the treatment of a patient who presented bruxism associated with GERD, usual acid food intake and smoking habit, generating severe tooth wear.

\section{CASE REPORT}

A 42-year-old smoker female patient came to the Dental School complaining of facial pain and a poor appearance of her teeth. Based in a visual analogue scale (VAS), the patient classified herself as having level 7 of orofacial pain. In addition, patient reported to suck lemon and eat spicy food daily. During clinical examination, good oral hygiene could be noted. The patient showed extreme corrosion of occlusal surfaces of the maxillary posterior teeth and the palatal surfaces of the maxillary anterior teeth (Figure 1). Anterior teeth presented extensive composite resin restorations, worn incisal edges with loss of restoration/enamel gloss at labial surfaces (Figure 1A), which is a characteristic appearance of exogenous corrosion. On the palatal surfaces, it was noted loss of enamel with smooth and shiny appearance, and worn incisal surfaces, suggesting bruxism activity. Posterior amalgam restorations were salient and fractured, being almost out of the teeth they were inserted in the past, due to enamel corrosion (Figures 1B and 1C). Mandibular teeth did not have important alterations at that moment, but the patient had already installed 3-element posterior fixed metal-ceramic prosthesis, full crows, one indirect partial metallic restoration, satisfactory amalgam restorations, and had no worn teeth (Figure 1D).

Based on clinical interview and clinical examination, worn teeth were related to the association among bruxism, perimolysis and exogenous corrosion by food habits. The patient's occlusion was clinically evaluated and it was found a decreased vertical dimension, secondary to bruxism and enamel erosion. The decreased vertical dimension and the absence of anterior and lateral guides seemed to be associated with muscular pain and difficult mandibular movements.

\section{Treatment Strategy}

After determining the etiologic factors, a multiphase treatment was proposed. Firstly, the patient was asked to settle an appointment with a gastroenterologist. Concomitantly, she was warned about her general and dental health, receiving nutritional instructions and counseling and information on the importance of reducing the smoking habit. In the second phase, the use of an occlusal splint to reestablish vertical dimension and control the muscular pain was indicated. The third phase was the esthetic functional rehabilitation with direct resin-based composite restorations, with definitive reestablishment of previously determined vertical dimension and anterior guidance. Occlusal adjustment and a second occlusal splint, comprising the last phase, are essential for good clinical longevity.

\section{Initial counseling and medical intervention}

The patient was advised about smoking consequences after and during dental treatment and also on general health. In addition, she was warned about her destructive bruxism habit and counseled to control it consciously during waking hours, as much as possible. After these simple initial counseling, the patient was referred to a gastroenterologist for medical consultation that confirmed GERD diagnosis. Endoscopy examination showed a hiatus hernia. The gastroenterologist prescribed Omeprazole $40 \mathrm{mg}$ /day to the patient and suggested her to elevate the head of her bed during sleeping and avoid acid, fatty and spicy food, especially right before bedtime. This was intended to provide a symptomatic relief and to discourage further progression of erosion. In these cases, after successful medical intervention, dental therapy is necessary to restore dental esthetics, form and function. 


\section{Occlusal splint: pain control and reestablishment of vertical dimension}

According to Kirveskari, et al. ${ }^{13}$ (1989), there is an association between occlusal interferences and signs of craniomandibular dysfunction. Therefore, in the present case, patient TMD signs and symptoms seemed to be related to tooth wear. As prosthetic rehabilitation aims at fulfilling optimal occlusal parameters, this situation cannot be postponed. Additionally, the lack of space in patients with reduced vertical dimension of occlusion makes any rehabilitation therapy impossible to be performed. In these situations, some authors have recommended occlusal splints for pain elimination because it is a reversible and efficient treatment approach ${ }^{12,30}$. An occlusal splint was fabricated enabling jaw position in centric relation of occlusion (CRO), occlusal stability and anterior guidance (Figure 2), controlling pain episodes ${ }^{30}$ and reestablishing vertical dimension. The occlusal splint was adjusted according to the parameters of an organic occlusion: the occlusal forces should be directed to the long axis of the posterior teeth (Figure 2A) and when posterior teeth occlude there should be no contact among upper and lower anterior teeth (and vice-versa) (Figures 2B, 2C and 2D); After using the splint for one week, the patient reported absence of pain episodes $(\mathrm{VAS}=0)$, which confirmed previous muscle pain diagnosis and occlusal splint efficiency. The occlusal splint was used for 90 days, with monthly clinical appointments (VAS $=0$ ).

\section{Esthetic restoration with composite resin}

After 90 days, the patient returned to continue the treatment. Again, she reported absence of muscle pain and TMJ comfort, which mean that a perfect adaptation to the correct vertical dimension of occlusion was obtained. The technique of choice for restoration of the worn teeth was the use of direct hybrid composite resin restorations ${ }^{26}$.

Alginate impressions were taken and the cast models were mounted in CRO on a semi-adjustable articulator by means of a jaw interference guide (JIG) device, intended either to act as an occlusion program changer or to facilitate the manipulation into $\mathrm{CRO}$ as it relaxes the musculature. The areas to be restored (Figure 3B) were waxed up on the models for diagnostic analysis of the desired occlusal relation (Figures 3A, 3C and 3D). The possibility of establishing uniform contacts during mandibular movements, correct dental contour and maintenance of a desirable stomatognathic system balance was verified during waxing of stone models (Figure 3). A lingual matrix was created with condensation silicone (Silon 2 APS, Dentsply, MD, USA) (Figure 4A) because this has been reported to be the ideal method to transfer the occlusal scheme obtained on the articulator to the clinical situation ${ }^{4}$. Teeth were restored according to the previous occlusal adjustment that was performed on the occlusal splint (Figure 5A). After restoration of a tooth quadrant, the splint was cut and occlusal adjustment was performed (Figures 5B, 5C and 5D).

The first step on an adhesive restoration is color selection. The teeth should be thorough cleaned with water/ pumice slurry prior to shade selection. Colors A3.5 and A3 for dentin and A2 for enamel were selected. The cavities prepared for corrosion/abrasion lesions are limited to the removal of preexistent restorations and carious tissue. Nevertheless, caries are generally an uncommon occurrence in patients with erosion, and teeth do not tend to retain plaque due to presence of smooth and polished surfaces ${ }^{7}$.

After pumice prophylaxis, enamel and dentin surfaces were etched with 35\% phosphoric acid (Scotchbond Etch gel, 3M-ESPE, St. Paul, MN, USA) for 15 seconds (Figure 4B). After rinsing with air/water spray for 20 seconds, an one-bottle adhesive (Adper Single Bond 2; 3M-ESPE, St. Paul, MN, USA) was applied, left untouched for 20 seconds, re-applied and light cured for 20 seconds (Figure 4C).

Hybrid composites better enable the reproduction of areas that receive normal occlusal load because they have a reinforcement of the organic matrix resulting on better physical properties ${ }^{27}$. Increments of the universal hybrid composite Filtek Z250 (3M-ESPE, St. Paul, MN, USA) were applied to the silicone matrix (shade A2) (Figure 4D), correctly positioned at the respective surfaces and light cured for 20 seconds in order to restore the palatal surfaces, simulating the lost enamel layer. On anterior teeth, dentin shade composite resin should be applied over the transition line between composite and tooth structure in order to mask this region. This composite resin is also applied to create the basic buccal tooth anatomy represented by dentin development lobes. A3.5 shade was used to create dentin lobes close to cervical tooth regions and A3 at mid third to incisal or occlusal surfaces (Figures 4E and 4F). Enamel was always restored with shade A2. Hybrid composite offers the resistance and opacity of dentin, contributing to the maintenance of the treatment and also enabling good esthetics.

\section{Occlusal adjustment}

Teeth were adjusted according to the same parameters used for occlusal splint installation (Figure 5A). These parameters tend to maintain a stable occlusion during many years ${ }^{17}$, being associated to a reduced occurrence of TMD's ${ }^{2}$. Some authors have recommended the employment of cephalometric tracing or computer generated axiography on reestablishing anterior guidance ${ }^{16}$. However, in this case, phonetic tests and an optimal occlusal adjustment produced good results with desirable function and elimination of disorder symptoms (muscle tenderness and TMJ sensivity). During occlusal adjustment, modifications are done on the surfaces of tooth, restorations or prostheses by means of selective wear or addition of restorative materials, seeking to harmonize maxillomandibular functional aspects in CRO and eccentric movements ${ }^{2}$. On this full-mouth rehabilitation case, selective wear of tooth surfaces was performed. It is of paramout importance to correctly adjust occlusion for greater treatment longevity ${ }^{17}$. For this, it is important to control the direction, magnitude, distribution and intensity of functional and parafunctional occlusal forces.

To develop the functional stability necessary for the success of the treatment, the dentist must evaluate the determinants of occlusion ${ }^{2}$. The muscles of mastication must 
be examined and palpated for tenderness. The condition of the TMJs should be evaluated. A determination of the relationship of the condylar guidance to the anterior guidance has to be evaluated in cases associated with severe anterior wear ${ }^{2}$. To meet all these requirements, the following criteria must be followed: the patient can function from centric relation to occlusion without occlusal interferences (Figure 6A); the TMJ is loaded without tenderness; there are posterior centric stops between the maxillary and mandibular arches before contact of anterior teeth; anterior coupling allows for disocclusion of posterior teeth (Figure $6 \mathrm{~B}, 6 \mathrm{C}$ and $6 \mathrm{D})$; teeth are positioned in balance with the tongue and facial muscles ${ }^{16}$.

\section{Finishing and polishing}

The precise individual anatomy is correctly determined during finishing and polishing procedures. Ultra-fine

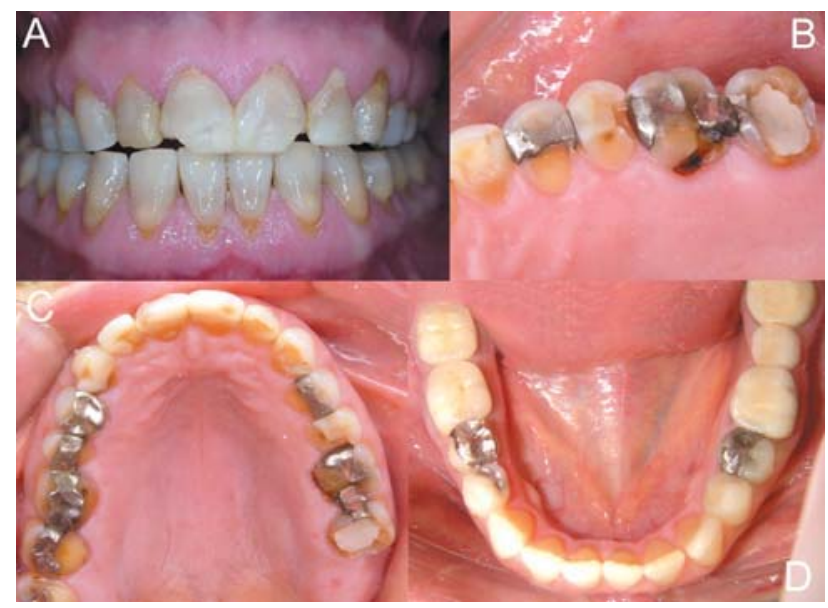

FIGURE 1- Initial aspect of the patient. A: extensive restorations on maxillary anterior teeth and worn incisal edges; B: corrosion of occlusal surfaces of maxillary posterior teeth; C: salient and fractured amalgam restorations; D: mandibular teeth with normal appearance

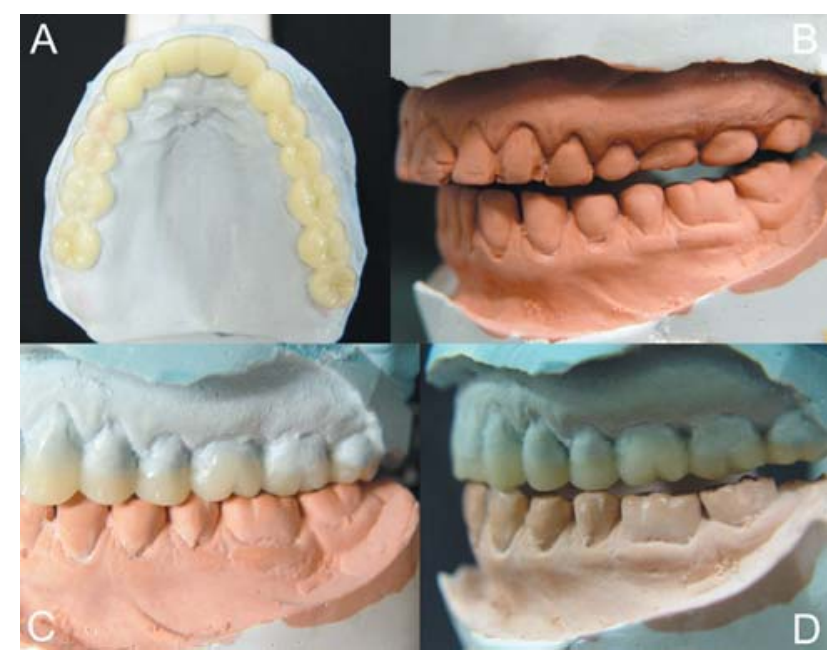

FIGURE 3- Cast models mounted in centric relation position. A: waxed model, upper view; B: space created to esthetic restorations; C: occlusion pattern obtained by waxing up; D: testing lateral guidance on waxed model diamond burs or multi-bladed burs are indicated to remove little excesses. After that, fine aluminum oxide discs (SofLex, 3M-ESPE, St. Paul, MN, USA) at low speed were used in order to achieve surface gloss and smoothness. To obtain restorations that reproduced the enamel surface texture a diamond bur was used, at low speed, and then only a superfine grit disc, resulting in an excellent final esthetic result.

\section{PATIENT FOLLOW-UP}

The patient was asked to attend scheduled in-office visits in order to check for the maintenance of the occlusal parameters and to certify that the restorations were in perfect function. After 1- and 2-year follow-up, correct function of the stomatognathic system was checked and new polishing

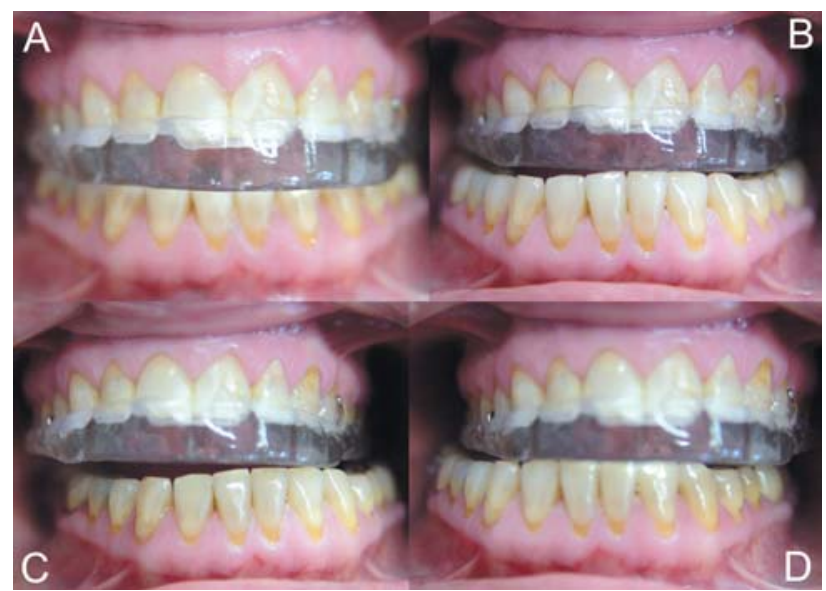

FIGURE 2- Occlusal splint. A: front view, recovering vertical dimension of occlusion; B: anterior guidance; C: left lateral guidance; D: right lateral guidance

performed (Figure 7). Patient was asked again about the

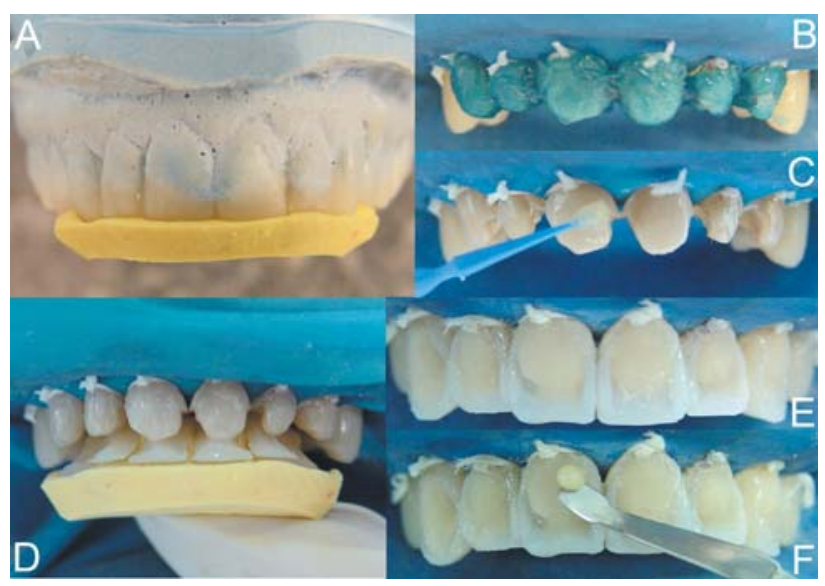

FIGURE 4- Restorative procedure. A: silicone matrix coping waxed areas of anterior teeth; B: acid etching with 35\% phosphoric acid; C: adhesive application; D: silicone lingual matrix and construction of palatal tooth surfaces; E,F: composite resin insertion, with enamel and dentin reproduction 


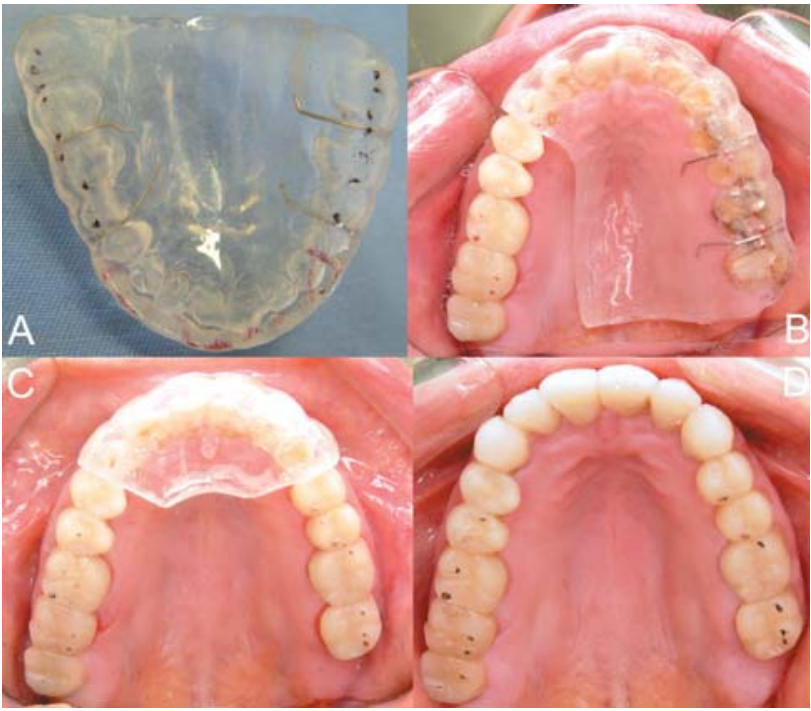

FIGURE 5- Occlusal splint during restorative procedures. A: occlusal adjustment with black spots denoting occlusal contacts and red spots denoting anterior guidances; B: restoration of posterior right teeth and occlusal adjustment of teeth/splint; C: restoration of all posterior teeth and occlusal adjustment of teeth/splint; D: restored teeth with adjusted occlusion

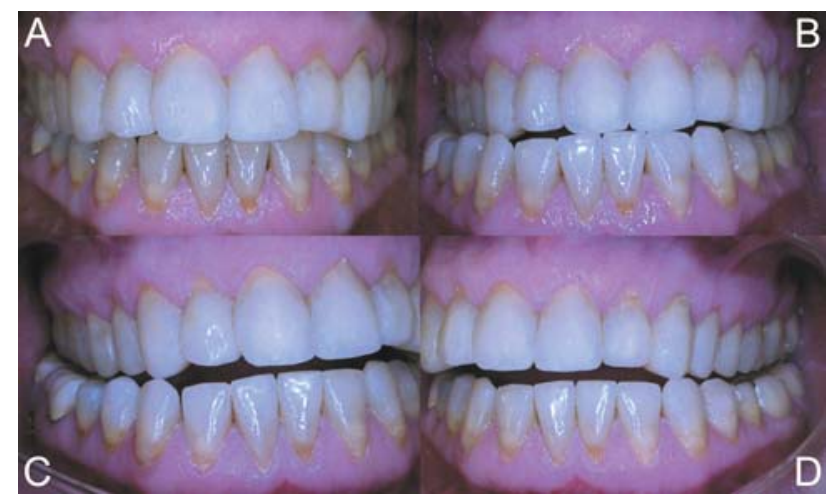

FIGURE 6- Functional aspects of restored teeth. A: view of restored teeth immediately after restoration; B: protrusion; C: right lateral guidance; D: left lateral guidance

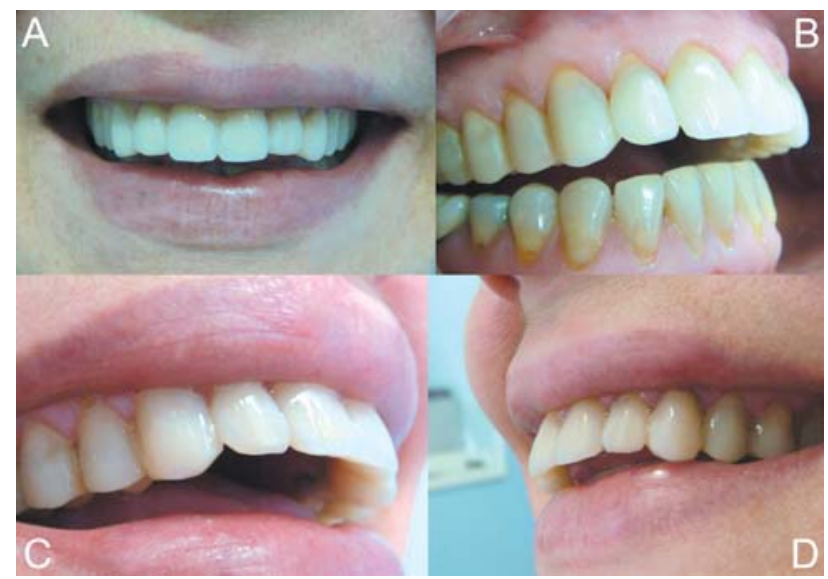

FIGURE 7- Esthetic results of oral rehabilitation follow-up after 2 years. A: Patient smile after new polishing; B: correct contour of posterior and anterior teeth; C,D: closer view of restored teeth remission of TMD symptoms and gastric disturbances. After 2-year follow-up she reported that pain had almost completely disappeared, but rare episodes of muscle tenderness could be noted (VAS $=1$ ). The sucking lemon habit was eliminated and gastroesophageal reflux disease was controlled by pharmacological therapy (which was reduced from daily use of Omeprazole $40 \mathrm{mg}$ to "if necessary") and elevation of the head of the bed during sleeping. However, the patient did not stop smoking.

\section{DISCUSSION}

Rehabilitation of severe cases of tooth wear is one of the most complex treatment modalities in dentistry because not only dentists should be involved, but also many other health professionals. In addition, patient compliance with the treatment is extremely important. The diagnosis may be faced as an important part of treatment and the patient can provide sufficient information (sometimes sensitive or embarrassing) to the clinician to allow for a differential diagnosis and to prevent further progression of these pathologies ${ }^{25}$. Worn dentitions are usually related to the presence of bruxism but its association with acid feeding, smoking habit and episodes of gastric reflow increases the loss of tooth structure leading to occlusal instability, reduced vertical dimension, muscle tenderness, TMJ pain and dysfunction ${ }^{18}$, as observed in this case. Thus, treatment plan must involve control of symptoms and removal of causes, as much as possible.

Bruxism involves local, systemic, psychological and hereditary factors and it has been demonstrated that dental treatment modalities may not completely eliminate its occurrence $^{10}$. The possibility of development of pain on TMJs or muscles is highly increased $^{20}$, but it these cases the masticatory function will certainly be already compromised. Thus, the patient needs to return into a healthy functional condition prior to any rehabilitation therapy ${ }^{28}$. Pharmacologic treatments and intraoral devices are some of these treatment modalities, and intraoral occlusal splints, as used in this case, seem to be an acceptable shortterm alternative ${ }^{12}$. For many years, splints were used only as bruxing guards for protection of tooth structure. However, as TMD therapies have evolved, various types and designs of splints have been developed to help counteracting the dysfunctional effects of bruxism, with the aim of correcting nonideal jaw and occlusal relationships ${ }^{23}$. These occlusal splints need to be adjusted to permit the establishment of normal occlusal parameters as if the patient had returned to a correct and ideal functional occlusal activity.

Occlusal balance by means of occlusal adjustment therapy is frequently used before and after a restorative procedure, after orthodontic therapy, after periodontal therapy, in an attempt to provide stable occlusal contacts during bruxism or clenching episodes, during correction of primary or secondary trauma and during TMD treatment ${ }^{5}$. The occlusal adjustment contributes to yielding a stable occlusion and comfort function for the stomatognathic 
system $^{8}$. Providing esthetics with the correct anterior guidance and occlusal contacts is the key to long-term occlusal stability ${ }^{16}$.

Depending on the degree of tooth wear, full-mouth rehabilitation of worn dentitions can be accomplished by conservative composite resin restorations, resin bonded ceramic crowns and post-and-core and cast restorations $\mathrm{s}^{3,14,24}$. The use of composite resins for severely worn dentitions is a relatively cost-effective option when patients cannot afford an expensive restorative rehabilitation, but a successful treatment is linked to patientrelated factors, such as oral hygiene and feeding habits ${ }^{7}$, treatment plan-related factors, including occlusal adjustment, bruxism control and GERD treatment ${ }^{17}$, in addition to the technique and materials to be employed ${ }^{21}$. Hybrid composites have good mechanical properties depending on their composition and polymerization modes $^{27}$. The use of these materials for restoration of worn teeth has been reported to last for a mean period of $5.0 \pm 3.0$ years, without any statistically significant difference from indirect metal-ceramic restorations or gold crowns, which last $5.9 \pm 2.6$ years on the average ${ }^{24}$. In spite of that, Van Nieuwenhuysen, et al. ${ }^{29}$ (2003), in a long-term evaluation of restorations from 1982 to 1999 , concluded that amalgam generally lasts 12.8 years before failure and composite resins last 7.8 years. It should be mentioned, however, that resin materials and associated techniques developed considerably since that time until current days.

Lemon juice and other plant food potassium salts can be used to treat gastric acidity due to systemic alkalinizing effects when metabolized in the large intestine ${ }^{22}$, and this may be of the reasons why the patient of this case had sucking lemon compulsion. Since smokers have a greater tendency to bruxism, it is always prudent to advise patients about the deleterious effect of smoking, in spite of the difficult in quitting. Smokers with trend to becoming bruxers can reduce the clinical longevity of restorations if occlusal stability is not protected. Thus, even with the installation of occlusal splints, it is important to recognize the signs of location and extent of damage to the teeth and the corrections that are necessary to reduce the wear caused by bruxism ${ }^{16}$. Abnormal occlusal conditions are present in many dental patients. However, they are often overlooked by dentists because of lack of knowledge or interest. Dentists should emphasize occlusion to better serve their patients and to provide more diversity in dental practice ${ }^{5}$. If dentists educate patients about the mechanism whereby bruxing habits physically overstress the stomatognathic system beyond its ability to adapt, they could understand their role in unknowingly causing the symptoms and could expect immediate relief from symptoms if these harmful habits were eliminated. The key to success is the accomplishment of a multidisciplinary treatment approach and an effective and constant communication with patients in such a way that they can thoroughly understand the problem and are given detailed instructions on how to stop the bruxing habits $^{23}$.

\section{REFERENCES}

1- Ali DA, Brown RS, Rodriguez LO, Moody EL, Nasr MF. Dental erosion caused by silent gastroesophageal reflux disease. J Am Dent Assoc. 2002;133(6):734-7; quiz 68-9.

2- Barbosa GAS, Badaró-Filho CR, Fonseca RB, Soares CJ, Neves FD, Fernandes AJ Neto. The role of occlusion and occlusal adjustment on temporomandibular dysfunction. Braz J Oral Sci. 2004;3(11):58994.

3- Barron RP, Carmichael RP, Marcon MA, Sandor GK. Dental erosion in gastroesophageal reflux disease. J Can Dent Assoc. 2003;69(2):849 .

4- Bernardo JK, Maia EA, Cardoso AC, Araujo EM Junior, Monteiro $\mathrm{S}$ Junior. Diagnosis and management of maxillary incisors affected by incisal wear: an interdisciplinary case report. J Esthet Restor Dent. 2002;14(6):331-9.

5- Christensen GJ. Abnormal occlusal conditions: a forgotten part of dentistry. J Am Dent Assoc. 1995;126(12):1667-8.

6- Christensen J. Effect of occlusion-raising procedures on the chewing system. Dent Pract Dent Rec. 1970;20(7):233-8.

7- Gandara BK, Truelove EL. Diagnosis and management of dental erosion. J Contemp Dent Pract. 1999;1(1):16-23.

8- Gray HS. Occlusal adjustment: principles and practice. N Z Dent J. 1994;90(399):13-9.

9- Grippo JO, Simring M, Schreiner S. Attrition, abrasion, corrosion and abfraction revisited: a new perspective on tooth surface lesions. J Am Dent Assoc. 2004;135(8):1109-18; quiz 63-5.

10- Harada T, Ichiki R, Tsukiyama Y, Koyano K. The effect of oral splint devices on sleep bruxism: a 6-week observation with an ambulatory electromyographic recording device. J Oral Rehabil. 2006;33(7):482-8.

11- House RC, Grisius R, Bliziotes MM, Licht JH. Perimolysis: unveiling the surreptitious vomiter. Oral Surg Oral Med Oral Pathol. $1981 ; 51(2): 152-5$.

12- Huynh NT, Rompre PH, Montplaisir JY, Manzini C, Okura K, Lavigne GJ. Comparison of various treatments for sleep bruxism using determinants of number needed to treat and effect size. Int $\mathrm{J}$ Prosthodont. 2006;19(5):435-41.

13- Kirveskari P, Alanen P, Jamsa T. Association between craniomandibular disorders and occlusal interferences. J Prosthet Dent. 1989;62(1):66-9.

14- Little JW. Eating disorders: dental implications. Oral Surg Oral Med Oral Pathol Oral Radiol Endod. 2002;93(2):138-43.

15- Madrid G, Madrid S, Vranesh JG, Hicks RA. Cigarette smoking and bruxism. Percept Mot Skills. 1998;87(3 Pt 1):898.

16- McIntyre F. Restoring esthetics and anterior guidance in worn anterior teeth: a conservative multidisciplinary approach. J Am Dent Assoc. 2000;131(9):1279-83.

17- Parker MW. The significance of occlusion in restorative dentistry. Dent Clin North Am. 1993;37(3):341-51.

18- Pavone BW. Bruxism and its effect on the natural teeth. J Prosthet Dent. 1985;53(5):692-6. 
19- Pergamalian A, Rudy TE, Zaki HS, Greco CM. The association between wear facets, bruxism, and severity of facial pain in patients with temporomandibular disorders. J Prosthet Dent. 2003;90(2):194200

20- Pullinger AG, Seligman DA, Gornbein JA. A multiple logistic regression analysis of the risk and relative odds of temporomandibular disorders as a function of common occlusal features. J Dent Res. $1993 ; 72(6): 968-79$.

21- Roeters JJ. Extended indications for directly bonded composite restorations: a clinician's view. J Adhes Dent. 2001;3(1):81-7.

22- Sabboh H, Coxam V, Horcajada MN, Remesy C, Demigne C. Effects of plant food potassium salts (citrate, galacturonate or tartrate) on acid-base status and digestive fermentations in rats. $\mathrm{Br} \mathrm{J}$ Nutr. 2007;98(1):1-6

23- Shulman J. Teaching patients how to stop bruxing habits. J Am Dent Assoc. 2001;132(9):1275-7.

24- Smales RJ, Berekally TL. Long-term survival of direct and indirect restorations placed for the treatment of advanced tooth wear. Eur $\mathrm{J}$ Prosthodont Restor Dent. 2007;15(1):2-6

25- Smith BG, Bartlett DW, Robb ND. The prevalence, etiology and management of tooth wear in the United Kingdom. J Prosthet Dent. $1997 ; 78(4): 367-72$

26- Soares CJ, Fonseca RB, Martins LR, Giannini M. Esthetic rehabilitation of anterior teeth affected by enamel hypoplasia: a case report. J Esthet Restor Dent. 2002;14(6):340-8.

27- Soares CJ, Pizi EC, Fonseca RB, Martins LR. Mechanical properties of light-cured composites polymerized with several additional post-curing methods. Oper Dent. 2005;30(3):389-94.

28- Soares CJ, Pizi EC, Fonseca RB, Martins LR, Fernandes AJ Neto. Direct restoration of worn maxillary anterior teeth with a combination of composite resin materials: a case report. J Esthet Restor Dent. 2005;17(2):85-91; discussion 2.

29- Van Nieuwenhuysen JP, D’Hoore W, Carvalho J, Qvist V. Longterm evaluation of extensive restorations in permanent teeth. J Dent. $2003 ; 31(6): 395-405$

30- Wassell RW, Adams N, Kelly PJ. The treatment of temporomandibular disorders with stabilizing splints in general dental practice: one-year follow-up. J Am Dent Assoc. 2006;137(8):108998; quiz 168-9. 